\title{
Examination of the relationship between management and clinician agreement on communication openness, teamwork, and patient satisfaction in the US hospitals
}

\author{
Olena Mazurenko*1, Jason Richter ${ }^{2}$, Abby Swanson-Kazley ${ }^{3}$, Eric Ford ${ }^{4}$ \\ ${ }^{1}$ Department of Health Policy and Management, University of Indiana, United States \\ ${ }^{2}$ Army-Baylor University, United States \\ ${ }^{3}$ Medical University of South Carolina, United States \\ ${ }^{4}$ Johns Hopkins Bloomberg School of Public Health, United States
}

Received: February 17, 2016

DOI: $10.5430 /$ jha.v5n $4 \mathrm{p} 20$
Accepted: April 17, 2016

Online Published: April 27, 2016

\begin{abstract}
Background: Patient satisfaction has always been an area of focus for hospitals, but gained particular importance due to the changes in the Centers for Medicare and Medicaid reimbursement policies. Hospital managers and clinicians interact with patients in different ways and have different perspectives on safety culture, yet little is known about how that impacts patient satisfaction. Objective: To examine how the agreement between clinicians and management perspectives on patient safety culture is related to patient satisfaction by employing cross-sectional design with linear regressions.

Methods: Two data sets were used: 2012 Hospital Survey on Patient Safety Culture and 2012 Hospital Consumer Assessment of Healthcare Providers and Systems (HCAHPS). The dependent variables were: overall rating of the hospital experience and willingness to recommend a hospital. The independent variables were four safety culture domains: communication openness, feedback, and communication about errors, teamwork within units, and teamwork between units.

Results: The results suggest that manager and clinician agreement on high levels of communication openness, feedback and communication about errors, teamwork between units, and teamwork across units were positively and significantly associated with overall patient satisfaction and willingness to recommend. Additionally, more favorable perceptions about patient safety culture by only clinicians yielded similar findings.

Conclusions: For policymakers, measuring managers and clinicians' perceptions on patient safety culture may provide a valuable indicator of patient satisfaction throughout the country. While managers are more likely to have the power to devote resources to patient safety initiatives, they may not adequately judge culture in their unit and should take into account the perspectives of clinicians who have a more frontline perspective.
\end{abstract}

Key Words: Patient satisfaction, Patient safety, Management, Clinician

\section{INTRODUCTION}

Improving patients' hospital experience has always been an area of focus for the hospitals. However, this topic is gain- ing particular importance as Value-Based Purchasing (VBP) takes a more central role in the Center for Medicare and Medicaid Services (CMS) reimbursement policies. ${ }^{[1]}$ In 2016, the

\footnotetext{
*Correspondence: Olena Mazurenko; Email: omazuren@iu.edu; Address: Department of Health Policy and Management, University of Indiana, United States.
} 
CMS' VBP Program is scheduled to withhold 1.75 percent of hospitals' inpatient payments, with that percentage increasing to two percent in 2017. Hospitals can earn back more than the amount withheld as a bonus if they perform well on key metrics - including patient satisfaction. The VBP payment amount includes patient satisfaction as a 25 percent weight in the formula that redistributes the withholdings. ${ }^{[2]}$ In 2015, 1,714 hospitals received bonuses above normal reimbursement, ranging from 0.01-2.09 percent, while 1,375 hospitals saw reductions of $0.01-1.24$ percent. ${ }^{[3]}$ The logic behind the program is to both reward and incentivize (i.e., penalize) performance to improve hospital quality. Previous evidence indicates that patient satisfaction is impacted by individual traits (patient's race/ethnicity, age, gender, etc.), organizational structures (hospital size, ownership status, etc.) and market-level characteristics (competition and resource availability). ${ }^{[4]}$ In addition to these factors, an organization's approach to patient safety may impact patient satisfaction.

Patient safety is a complex issue that involves all healthcare team members to accomplish better quality outcomes, such as decreasing rates of adverse events leading to patient harm (e.g., wrong site surgery, drug-drug interactions, etc.) or improving patient satisfaction. Effective teamwork, open communication, and interprofessional collaboration are crucial for achieving high quality and safety in healthcare. ${ }^{[5]}$ Previous research has found that in hospitals where staff members, in the aggregate, have more positive patient safety culture perceptions, customers are more likely to express satisfaction with their care. ${ }^{[6]}$ Given the diversity of perspectives and roles of health care professionals, teamwork and communication are likely necessary antecedents of quality care. Evidence indicates that it is not unusual for healthcare team members (e.g. physicians versus management staff) to have very different perceptions about the safety culture in their organization. For instance, Huang and colleagues (2007) reported that nursing directors tend to overestimate their personnel's safety culture scores, particularly for teamwork climate and working conditions. ${ }^{[7]}$ Elevated variation in patient safety perceptions among healthcare team members is correlated with adverse patient outcomes. Singer, et al. found that perceptions of the safety culture of frontline clinical staff were related to adverse medical events, although the same was not true of managers. ${ }^{[8]}$ Vogus claims that there is not one single safety climate and that safety climate may promote rivalry and conflict between professions instead of harmony and integration. ${ }^{[9]}$ Vogus further states that perspective related to safety climate may be based on differentiation (between professions, departments, hierarchies, etc.) or fragmentation, in which culture is unclear and ambiguous. ${ }^{[9]}$

Given how previous research found differences between clinPublished by Sciedu Press ical staff and manager perceptions of safety culture, the purpose of this study is to examine whether those differences are related to customer satisfaction scores in a nationally representative sample of US hospitals. Specifically, we examine the agreement between the clinical staff members' and managers' perspectives on communication openness, teamwork between and within units and the associations with patients' overall rating of the hospital and willingness to recommend a hospital. We did not identify existing research that examined differences in perceptions of safety culture between these groups, and how those differences affect patient satisfaction.

\section{METHODS}

A cross-sectional study design is used to examine the relationship between hospitals' safety culture and patient satisfaction. The data were drawn from two secondary sources: (1) the 2012 Hospital Survey on Patient Safety Culture (HSOPS), collected by Agency for Healthcare Research and Quality (AHRQ); and (2) the 2012 Hospital Consumer Assessment of Healthcare Providers and Systems (HCAHPS) survey, collected by CMS. The HSOPS data is collected from the hospitals in all 50 states plus U. S. territories. The HSOPS survey has been proven to be a reliable instrument that could be used at multiple levels of analysis. The survey instrument could be found at: www.ahrq.gov/professionals/qua lity-patient-safety/patientsafetyculture/hos pital/index.html. Each hospital staff member (clinicians, managers) was asked to assess patient safety culture in their clinical area or unit. Our dataset had surveys completed by the hospital staff from 2012, with survey data being aggregated to the hospital level.

Patient satisfaction items were obtained from the HCAHPS survey, which is collected by Center for Medicare and Medicaid. ${ }^{[10]}$ The HCAHPS survey contains 10 patient perspectives on care: communication with doctors, communication with nurses, the responsiveness of hospital staff, pain management, communication about medicines, communicating about home recovery, cleanliness of the hospital environment, the quietness of the hospital environment, and transition of care. It is administered to a random sample of adult inpatients between 48 hours and six weeks after discharge. The response rate for HCAHPS was 33 percent in 2012. ${ }^{[11]}$

We used the Medicare identification numbers to merge these two datasets. In our study, the unit of analysis is a hospital. As a result, only hospitals that had Medicare identifier in both datasets were included in our analytical sample. Based on the previous literature ${ }^{[12]}$ HSOPS survey can measure group culture and not solely individual attitudes, thus enabling us to use these data to test our hypotheses. 
Linear regression is used to compare the variables of interest (i.e., patient safety culture items) with the customer satisfaction measures. Our dependent variables were two HCAHPS patient satisfaction measures: (1) overall rating of the hospital, and (2) willingness to recommend a hospital. Specifically, each variable is presented as the percentage of patients, for a given hospital, who ranked their level of satisfaction in the highest category for this item. For example, the patient had ten options to choose from when was asked about the overall rating of the hospital: zero (worst possible hospital) to 10 (best hospital possible). For the current analysis, the percentage of patients who selected ten was used, e.g. "best hospital possible". Similarly, our willingness to recommend variable represents the percentage of the patients who indicated that they would "definitely recommend this hospital to friends and family". This approach is consistent with previous literature that examined patient satisfaction using HCAHPS dataset. $^{[13,14]}$

Our main independent variables were four patient safety culture domains (communication openness, feedback, and communication about errors, teamwork within units, and teamwork between units) derived from the HSOPS survey.
These domains were chosen due to a previously established relationship between the culture of communication and teamwork and customer satisfaction in the general management literature. ${ }^{[15]}$ The survey items have a five-point Likert scale with types of response choices (strongly disagree to strongly agree) or frequency (never to always). For each survey question, we recoded the Likert scale responses into binary, with strongly agree/always and agree on/most of the time being coded as one and the rest is zero. Next, we calculated the overall percent positive score for each domain by using an average of individual variables that comprised this domain. The domains are comprised of three-to-four related survey questions, with high levels of agreement among the questions. ${ }^{[16]}$ The survey instrument and the questions that make up each domain can be found at: www.ahrq.gov/p rofessionals/quality-patient-safety/patients afetyculture/hospital/index.html. Percent positive scores had a possible range of 0 to 100 . This approach has been used in the literature and has been shown to improve interpretability of study results. ${ }^{[17]}$ Third, each hospital was assigned into one of the four possible groups based on the agreement/disagreement between managers and clinical staff on patient safety (see Table 1).

Table 1. Groups formed based on the managers and clinicians' agreement/disagreement on patient safety culture

\begin{tabular}{|c|c|c|}
\hline \multirow{2}{*}{$\begin{array}{l}\text { Managers think patient } \\
\text { safety culture is high }\end{array}$} & \multicolumn{2}{|l|}{ Clinicians think patient safety culture is high } \\
\hline & Yes & No \\
\hline Yes & $\begin{array}{l}\text { Group 1: Hypothesis is that hospitals that share high } \\
\text { perceptions of patient safety, for both managers and } \\
\text { clinicians, will have higher levels of patient satisfaction, } \\
\text { compared to hospitals that share low perceptions of patient } \\
\text { safety. }\end{array}$ & $\begin{array}{l}\text { Group 3: Hypothesis is that hospitals that have high perceptions } \\
\text { of patient safety in only the management group will have not } \\
\text { have significantly higher levels of patient satisfaction, compared } \\
\text { to hospitals that share low perceptions of patient safety in both } \\
\text { the management and clinician groups. }\end{array}$ \\
\hline No & $\begin{array}{l}\text { Group 4: Hypothesis is that hospitals that have high } \\
\text { perceptions of patient safety in only the clinician group } \\
\text { will have have significantly higher levels of patient } \\
\text { satisfaction, compared to hospitals that share low } \\
\text { perceptions of patient safety in both the management and } \\
\text { clinician groups. }\end{array}$ & $\begin{array}{l}\text { Group 2: Hypothesis is that hospitals that share low perceptions } \\
\text { of patient safety, for both managers and clinicians, will have } \\
\text { lower levels of patient satisfaction, compared to hospitals that } \\
\text { share high perceptions of patient safety. }\end{array}$ \\
\hline
\end{tabular}

We defined clinical staff as those individuals that identified their staff position as a physician, physician assistant, nurse practitioner, registered nurse, licensed practical nurse or medical assistant. The management group was comprised of staff that selected administration/management as a staff position. Each individual response was categorized as either "high" (above the median) or "low" (below the median) based on its position to the median. The following four groups were formed: (1) managers and clinical staff agree that patient safety culture is high in their unit (Group 1); (2) managers and clinical staff agree that patient safety culture is low in their unit (Group 2); (3) managers perceive that safety cul- ture is high, but clinicians perceive that it is low (Group 3); (4) managers perceive that safety culture is low, but clinicians perceive that it is high. We placed hospitals in a group for each of the four safety culture domains.

In line with previous patient satisfaction research ${ }^{[18,19]}$ the following control variables were included in our analysis: hospital size (measured as number of staffed beds, e.g. below and above 100 beds), ownership (for-profit, not-for-profit; governmental), geographic location (urban, rural), teaching status (whether or not the organization is a member of the Council of Teaching Hospitals and Health Systems), system membership (part of a system or independent), US region 
based on census categories (Northeast, Southeast, Midwest, West), and high-technology index (a summated scale representing the presence of high-tech services including cardiac catheterization laboratory, open heart surgery, extracorporeal shock-wave lithotripter, megavoltage radiation therapy, nuclear magnetic resonance imaging, organ/tissue transplant, Neonatal intensive care, certified trauma center). ${ }^{[20]}$

\section{RESUlts}

Our analytical sample consisted of 181 hospitals that reported patient satisfaction measures to CMS and submitted the HSOPS survey to AHRQ. A total of 5,919 responses from managers and 36,573 responses from clinical staff regarding patient safety were available for our analysis. Table 2 displays the organizational and geographical characteristics of hospitals included in the analysis. Briefly, 140 (75.5\%) were non-profit, $122(66 \%)$ teaching, 140 (76\%) were members of a hospital system, and $145(80 \%)$ located in urban areas. The characteristics of the hospitals in this final sample were consistent with the overall distribution of hospitals registered with the American Hospital Association with respect to teaching status, owner- ship, geographic region, and bed size.

Table 2. Descriptive characteristics of the sample $(\mathrm{N}=181)$

\begin{tabular}{lll}
\hline Organizational level characteristics & & N (\%) \\
\hline \multirow{2}{*}{ Bed size } & $<100$ beds & $75(41.5)$ \\
& $>100$ beds & $106(58.5)$ \\
Ownership & For-profit & $20(11)$ \\
& Non-profit & $138(76.3)$ \\
Teaching status & Governmental & $23(12.7)$ \\
System membership & Yes & $118(65.2)$ \\
& No & $63(34.8)$ \\
Geographic location & Yes & $138(76.3)$ \\
High-technology index, M (SD) & No & $43(23.6)$ \\
& Urban & $144(79.7)$ \\
Census divisions & Rural & $37(20.3)$ \\
& West & $3.55(2.2)$ \\
& Midwest & $24(13.2)$ \\
Patient satisfaction measures & Northeast & $87(48.4)$ \\
& South & $5(2.7)$ \\
& Nurse communication, M (SD) & $65(35.7)$ \\
& Doctor communication, M (SD) & $78.9(4.55)$ \\
& Discharge information, M (SD) & $81.1(4.45)$ \\
& Communication about medications, M (SD) & $84.4(4.66)$ \\
& & $62.9(5.51)$ \\
\hline
\end{tabular}

Table 3. Number of hospitals in each group by patient safety domain/N (\%)

\begin{tabular}{lllll}
\hline Groups & Communication openness & Feedback & Teamwork within units & Teamwork across unit \\
\hline Group 1 & $55(30.4)$ & $59(32.6)$ & $55(30.4)$ & $58(32.1)$ \\
Group 2 & $54(29.8)$ & $59(32.6)$ & $56(30.8)$ & $58(32.1)$ \\
Group 3 & $37(20.4)$ & $32(17.6)$ & $35(19.4)$ & $33(18.2)$ \\
Group 4 & $35(19.4)$ & $31(17.2)$ & $35(19.4)$ & $32(17.6)$ \\
Total & $181(100)$ & $181(100)$ & $181(100)$ & $181(100)$ \\
\hline
\end{tabular}

Note. Group 1: Managers and clinicians agree that patient safety culture is high in their unit; Group 2: Managers and clinicians agree that patient safety culture is low in their unit; Group 3: Managers perceive that safety culture is high, but clinicians perceive that it is low; Group 4: Managers perceive that safety culture is low, but clinicians perceive that it is high

Hospital group composition is presented in Table 3. About thirty percent of the hospitals had managers and clinical staff agree that patient safety culture is high in their unit
(Group 1). About twenty percent of the hospitals had their clinical staff and managers agree that the patient safety culture is low in their unit (Group 2). The managers and clinical 
staff disagreed about patient safety culture in the remainder of the hospitals (Groups 3 and 4).

A bivariate analysis of the relationship between patient satisfaction scores and four groups that represented agreement or disagreement between managers and clinical staff on the safety culture showed significant differences. Generally, hospitals where managers and clinical staff both rated their safety culture as high (Group 1), or where only clinicians perceived the safety culture as high (Group 4), had significantly higher patient satisfaction scores, as compared to hospitals where both managers and clinicians perceived the safety culture as low (Group 2). For instance, overall rating of the hospital (Group 1: 72 versus 65, $p$-value $=.001$; Group 4: 73 versus $65, p$-value $=.001)$, and willingness to recommend a hospital (Group $1 \&$ Group 4: 77 versus 73, $p$-value $=.05$ ) were significantly higher in hospitals where managers and clinical staff were in agreement (Group 1) or where only clinicians perceived a high degree of communication openness (Group 4).

Table 4. Results of weighted least squares regression: relationships between four patient safety groups and patient satisfaction among US hospitals $(\mathrm{N}=181)$

\begin{tabular}{|c|c|c|c|c|c|}
\hline \multirow{2}{*}{\multicolumn{2}{|c|}{ Patient satisfaction }} & \multicolumn{4}{|c|}{ Patient safety culture domains: agreement/disagreement between clinicians and managers perceptions } \\
\hline & & Communication openness & Feedback & Teamwork within units & Teamwork across units \\
\hline \multirow{3}{*}{ Group 1} & Overall rating & $5.95^{* * *}$ & $4.49^{* * * *}$ & $4.83^{* * *}$ & $2.74^{* *}$ \\
\hline & Willingness to recommend & $4.98^{* * *}$ & $5.76^{* * *}$ & $5.01^{* *}$ & $5.47^{* * * *}$ \\
\hline & Adjusted $R^{2}$ & 0.29 & 0.27 & 0.31 & 0.26 \\
\hline \multirow{3}{*}{ Group 3} & Overall rating & -0.77 & 3.77 & 1.82 & 1.66 \\
\hline & Willingness to recommend & -1.18 & 3.18 & 0.20 & 1.60 \\
\hline & Adjusted $R^{2}$ & 0.32 & 0.23 & 0.22 & 0.21 \\
\hline \multirow{3}{*}{ Group 4} & Overall rating & 2.16 & $3.34^{* *}$ & $3.31^{*}$ & $4.48^{* * *}$ \\
\hline & Willingness to recommend & 2.32 & $5.08^{* * *}$ & $6.54^{* * * *}$ & $5.50^{* *}$ \\
\hline & Adjusted $R^{2}$ & 0.29 & 0.28 & 0.27 & 0.26 \\
\hline
\end{tabular}

Note. High-tech index is a summated scale representing the presence of high-tech services including cardiac catheterization laboratory, open heart surgery, extracorporeal shock-wave lithotripter, megavoltage radiation therapy, nuclear magnetic resonance imaging, organ/tissue transplant, Neonatal intensive care, certified trauma center; ${ }^{*} p<.1 ; * * p<.05 ;{ }^{* * *} p<.01$; Group 1: Managers and clinicians agree that patient safety culture is high in their unit; Group 2: Managers and clinicians agree that patient safety culture is low in their unit (Reference group); Group 3: Managers perceive that safety culture is high, but clinicians perceive that it is low; Group 4: Managers perceive that safety culture is low, but clinicians perceive that it is high.

Table 4 reports the results of our ordinary least squares multiple regression analysis by safety group. Group 2, in which managers and clinical staff agree that patient safety culture is low in their unit serves as a reference group for analyses presented below. After controlling for hospital and geographical characteristics, we found that patient satisfaction was higher if managers and clinical staff agreed patient safety culture is high (Group 1), or if only clinicians perceived the culture as high (Group 4). Specifically, manager and clinician agreement on high levels of communication openness (overall rating $\beta=5.95, p$-value $=.001$; willingness to recommend $\beta=4.98, p$-value $=.001)$, feedback and communication about errors $(\beta=4.49, p$-value $=.001 ; \beta=5.76$, teamwork within unit $p$-value $=.001)$, teamwork within unit $(4.83$, $p$-value $=.001 ; \beta=5.01, p$-value $=.01)$, and teamwork across units $(\beta=2.74, p$-value $=.05 ; \beta=5.47$, $p$-value $=.01)$ were positively and significantly associated with overall rating of the hospital and willingness to recommend. Additionally, more favorable perceptions about patient safety culture by only clinicians yielded similar findings. Specifically, clinician perception on high levels of feedback and communication about errors (overall rat- ing: $\beta=3.34, p$-value $=.05$; willingness to recommend: $\beta=5.08, p$-value $=.001)$, teamwork within unit (overall rating: $\beta=3.31, p$-value $=.05$; willingness to recommend: $\beta=6.54, p$-value $=.001$ ), and teamwork across units (overall rating: $\beta=4.48, p$-value $=.05$; willingness to recommend: $\beta=5.50, p$-value $=.05$ ) were positively and significantly associated with overall rating of the hospital and willingness to recommend.

\section{Discussion}

Health outcomes and patient satisfaction play increasingly influential roles in hospital success and Medicare reimbursements. Our study's main findings indicate that clinical staff perceptions more closely link to patient satisfaction than perceptions of management. Our study found hospitals, where only clinicians had high teamwork and communication culture perceptions, had higher patient satisfaction scores than hospitals where these perceptions were low. We did not find that the same relationship in hospitals where only managers had high teamwork and communication perceptions. Clinicians spend more time interacting with patients and more accurately represent the patient safety issues that could adversely affect patient satisfaction. These findings are con- 
sistent with previous research that examined perceptions of safety culture on patient safety indicators (PSIs) and found that the perceptions of frontline staff more accurately link to patient to PSIs. ${ }^{[8]}$ Our research indicates that is also true when the outcome is patient satisfaction. We also found that when managers and clinical staff agree that communication and teamwork culture is high in their unit, patient satisfaction is increased. This relationship indicates that patients can perceive the importance and presence of a culture that promotes patient safety and value it when assessing their care in the hospital. These findings may also be a result of shared sense of context and understanding that patient safety is a collective responsibility among hospital staff, or they may indicate that such agreement is also indicative of better teamwork and communication related to patient care (i.e. agreement indicates that everyone works together for the best outcomes). Our results are in line with previous research that examined the relationship between hospital staff perceptions of patient safety culture and patient satisfaction. ${ }^{[6]}$

Our study also found hospitals, where clinicians had high teamwork and communication culture perceptions, had higher patient satisfaction scores than hospitals where these perceptions were low. We did not find that the same relationship in hospitals where only managers had high teamwork and communication perceptions. Clinicians spend more time interacting with patients and are more likely to observe the patient safety issues that could adversely affect patient satisfaction. Therefore, hospital managers must be cognizant that their perceptions may not mirror those of their frontline clinical staff. Since clinical staff perceptions of safety culture are more closely tied to patient satisfaction, managers should periodically assess safety culture in their units, and take efforts to improve the perceptions of clinical staff. These findings are consistent with previous research that examined perceptions of safety culture on patient health outcomes. ${ }^{[8]}$

These findings support the case for the value of teamwork and communication in hospitals. Given these results, current hospital leaders may wish to allocate additional resources to improve teamwork skills and communication in hospitals due to their relationship to patient safety and satisfaction. The findings may also guide leaders to examine and improve a culture that leads managers and clinicians into an agreement related to communication. For example, given the complex and interprofessional nature of health care, cultures that promote collaboration, communication, and teamwork are likely to see higher performance in the areas of patient safety and satisfaction. Given the current reimbursement practices, this will also be translated into better financial performance.

Team training has been consistently identified across studies

Published by Sciedu Press as a way to improve teamwork culture. ${ }^{[21]}$ Similarly, mechanisms to support team communication, such as the Comprehensive Unit-Based Safety Program, have been shown to improve teamwork and communications in hospitals. Other programs have focused on fostering respect and an appreciation of interprofessional collaboration. Such programs may promote teamwork and communication by placing value on the contributions of diverse groups of professions, where each brings a different perspective to the patient's care. One way organizations can improve is to first assess the culture through a survey tool such as HSOPS, and then provide feedback to all staff. Often, it is simply top management that views survey results and does not distribute them to other frontline staff. ${ }^{[22]}$ Both managers and clinical staff should participate in feedback sessions for most effective change to occur. ${ }^{[23]}$

On the other hand, there have been studies that show that many strategies for improving patient safety culture in hospitals are ineffective or have limited impact, and one can certainly see how diverse professions with varying values and training may not share perspective. ${ }^{[24]}$ These strategies have included leadership walk around, structured educational programs, team-based strategies, simulation-based training programs, multi-faceted unit-based programs, multicomponent organizational interventions, and qualitative data and implementation lessons. ${ }^{[24-31]}$ Such efforts illustrate the difficulty of cultural change and the challenge of creating high-reliability organizations related to patient safety. ${ }^{[32]}$ Strategies that might improve teamwork, leadership, and patient safety should be flexible and multifaceted, and additional research is needed to identify specific strategies that consistently work to improve patient safety culture.

Our findings should be of interest to healthcare practitioners, policymakers, and researchers who seek to improve patient safety and satisfaction in their hospital. Healthcare practitioners could use our findings to justify the allocation of additional resources to patient safety, as it would lead to improvements in other aspects of quality, such as patient satisfaction, which are now tied to reimbursement. Our findings may also guide leaders to examine and improve a culture that leads managers and clinicians into an agreement related to communication.

\section{Study limitations and future research}

There are several limitations to our analysis. First, little is known about clinical staff ability to adequately judge the patient experience depending on their level of involvement with the patient, such as registered nurses versus physicians. Future research should examine this issue further. Specifically, a physician may spend less time interacting with a patient, 
and thus be less aware of patient experience during the hospital stay. Second, our study relied on cross-sectional data, thus our results could be interpreted as associations only. $\mathrm{Fu}$ ture research should employ longitudinal design to examine the causal nature of the relationships between patient safety and patient satisfaction. Alternatively, instrumental variables might be employed to assess causality. Future research should also explore how differences in staff perceptions of safety culture influence patient safety outcomes.

\section{Conclusions}

Policies aimed at improving patient satisfaction should recognize the importance of agreement and collaboration between clinicians and managers on patient safety. Although managers are more likely to have the power to devote resources to patient safety initiatives, they may not adequately judge culture in their unit and should take into account the perspectives of clinicians who have a more frontline perspective on patient care. Managers should become aware of their limitations and closely track clinical staff perceptions. The relationship between patient safety culture and patient satisfaction also supports the business case for improved communication and teamwork. Given that reimbursement is now tied to patient satisfaction, any measures to improve patient safety culture through teamwork and communication training are a worthy investment.

\section{REFERENCES}

[1] McGinty G. Is Value-Driven Health Care an Unfunded Mandate for Radiologists? American Journal of Roentgenology. 2016; 206(2): 280-282. PMid: 26797354. http://dx.doi.org/10.2214/AJR .15 .15399

[2] Ginsburg PB, Wilensky GR. Revamping Provider Payment in Medicare. Forum for Health Economics and Policy. 2015.

[3] Rice S. Hospitals ponder meaning, value of CMS' new star ratings. Modern Healthcare. 2015. Available from: http://www.modern healthcare.com/article/20150416/NEWS/150419925?utm _source=modernheal thcare\&utm_medium=email\&utm_conte nt $=20150416$-NEWS-150419925\&utm_campaign=dos

[4] Kazley AS, Diana ML, Ford EW, et al. Market Factors Related to of Hospitals' Patient Satisfaction Ratings. Journal of Hospital Administration. 2015; 4(4): 23-34. http://dx.doi.org/10.5430/jha.v $4 \mathrm{n} 4 \mathrm{p} 40$

[5] Birkmeyer NJ, Finks JF, Greenberg CK, et al. Safety culture and complications after bariatric surgery. Annals of surgery. 2013; 257(2): 260-265. PMid: 23047607. http://dx.doi.org/10.1097/SLA $.0 \mathrm{~b} 013 \mathrm{e} 31826 \mathrm{c} 0085$

[6] Sorra J, Khanna K, Dyer N, et al. Exploring relationships between patient safety culture and patients' assessments of hospital care. Journal of Patient Safety. 2012; 8(3): 131-139.

[7] Huang DT, Clermont G, Sexton JB, et al. Perceptions of safety culture vary across the intensive care units of a single institution. Critical Care Medicine. 2007; 35(1): 165-176.

[8] Singer S, Lin S, Falwell A, et al. Relationship between safety climate and safety performance in hospitals. Health services research. 2009; 44(2p1): 399-421.

[9] Vogus TJ. Safety climate strength: a promising construct for safety research and practice. BMJ Quality and Safety. 2016 [Epub ahead of print].

[10] Werner RM, Bradlow ET. Relationship between Medicare's hospital compare performance measures and mortality rates. Journal of American Medical Association. 2006; 297(22): 8. http://dx.doi.org $/ 10.1001 /$ jama. 296.22.2694

[11] Centers for Medicare \& Medicaid Services. Summary of HCAHPS Survey Results. 2016.

[12] Smits M, Wagner C, Spreeuwenberg P, et al. Measuring patient safety culture: An assessment of the clustering of responses at unit level and hospital level. Quality and Safety in Health Care. 2009; 18(4):
292-296. PMid: 19651934. http://dx.doi.org/10.1136/qshc . 2007.025965

[13] Jha AK, Orav EJ, Zheng J, et al. Patients' perception of hospital care in the United States. New England Journal of Medicine. 2008; 359(18): 1921-1931.

[14] Kazley AS, Diana ML, Ford EW, et al. Is electronic health record use associated with patient satisfaction in hospitals? Health Care Management Review. 2012; 37(1): 23-30.

[15] Tornow WW, Wiley JW. Service quality and management practices: A look at employee attitudes, customer satisfaction, and bottom-line consequences. People and Strategy. 1991; 14(2): 105-112.

[16] Sorra J, Nieva VF. Psychometric analysis of the hospital survey on patient safety. Final Report to Agency for Healthcare Research and Quality (AHRQ). Washington: AHRQ; 2003.

[17] Richter JP, McAlearney AS, Pennell ML. The influence of organizational factors on patient safety: Examining successful handoffs in health care. Health Care Management Review. 2014; 23: 121-139.

[18] Ford EW, Huerta TR, Diana ML, et al. Patient satisfaction scores and their relationship to hospital website quality measures. Health Market Quarterly. 2013; 30(4): 334-348. PMid: 24308412. http: //dx.doi.org/10.1080/07359683.2013.844041

[19] Tajeu GS, Kazley AS, Menachemi N. Do hospitals that do the right thing have more satisfied patients? Health Care Management Review. 2014; 34-45.

[20] Zuckerman S, Hadley J, Iezzoni L. Measuring hospital efficiency with frontier cost functions. Journal Health Economics. 1994; 13: 255-280, 335-240.

[21] Weaver SJ, Lubomksi LH, Wilson RF, et al. Promoting a culture of safety as a patient safety strategy: a systematic review. Annals of internal medicine. 2013; 158: 369-374.

[22] Nieva VF, Sorra J. Safety culture assessment: A tool for improving patient safety in healthcare organizations.Quality \& Safety in Health Care. 2003; 12(2): ii17-23. http://dx.doi.org/10.1136/qhc .12.suppl_2.ii17

[23] Hinrichs J. Feedback, action planning, and follow-through. Organizational surveys: tools for assessment and change. San Francisco: Jossey-Bass; 1996. 255-79 p.

[24] Morello RT, Lowthian JA, Barker AL, et al. Strategies for improving patient safety culture in hospitals: a systematic review. BMJ Quality and Safety. 2013; 22: 11-18. PMid: 22849965. http: //dx.doi.org/10.1136/bmjqs-2011-000582 
[25] Pronovost P, Weast B, Rosenstien B, et al. Implementing and validating a comprehensive unit-based safety program. Journal of Patient Safety. 2005; 1: 33-40.

[26] Thomas EJ, Sexton JB, Neiland TB, et al. The effect of executive walk arounds on nurse safety climate attitudes: a randomized trial of clinical units. BMC Health Services Research. 2005; 5: 28. PMid: 15823204. http://dx.doi.org/10.1186/1472-6963-5-28

[27] Cooper JB, Blum RH, Carroll JS, et al. Differences in safety climate among hospital anesthesia departments and the effect of a realistic simulation-based training program. Anesthiology Analgesics. 2008; 106: 574-84. PMid: 18227319. http://dx.doi.org/10.1213/0 1. ane.0000296462.39953.d3

[28] O'Leary KJ, Wayne DB, Haviley C, et al. Improving teamwork: impact of structured interdisciplinary rounds on a medical teaching unit. Journal of General Internal Medicine. 2010; 25: 826-32. PMid: 20386996. http://dx.doi.org/10.1007/s11606-010 $-1345-6$
[29] Bleakley A, Boyden J, Hobbs A, et al. Improving teamwork climate in operating theaters the shift from multiprofessionalism to interprofessionalism. Journal of Interprofessional Care. 2006; 20: 461-470. PMid: 17000472. http://dx.doi.org/10.1016/j.healthpol .2009 .02 .007

[30] Hellings J, Schrooten W, Klazinga NS, et al. Improving patient safety culture. International Journal of Health Care Quality Assurance. 2010; 23: 489-506. PMid: 20845679. http://dx.doi.org/10.1108/0 9526861011050529

[31] The Health Foundation. Safer Patients Initiative phase one 1. 2011. Available from: http://www.health.org.uk/publication/sa fer-patients-initiative-phase-1

[32] Vogus TJ, Hilligoss B. The underappreciated role of habit in highly reliable healthcare. BMJ Quality and Safety. 2016; 3: 141-6. PMid: 26337423. http://dx.doi.org/10.1136/bmjqs-2015-00451 2 